\title{
ARQUITETURA COMO PROMOTOR SOCIAL: CENTRO DE ARTES E ESPORTES UNIFICADOS - CONJUNTO HABITACIONAL “JARDIM JOÃO DOMINGOS NETTO”, PRESIDENTE PRUDENTE - SP
}

\author{
Ana Caroline de Oliveira, Korina Aparecida Teixeira Ferreira da Costa
}

Universidade do Oeste Paulista - UNOESTE, Curso de Arquitetura e Urbanismo, Presidente Prudente, SP. E-mail: caroline18oliveira@hotmail.com

\section{RESUMO}

Os Centros Educacionais Unificados - CEUs, são equipamentos urbanos voltados para a ampliação da inserção social de comunidades segregadas na sociedade, mediante oferta de educação, cultura, esporte, lazer e cursos profissionalizantes. O objetivo deste trabalho foi a compreensão de como a arquitetura juntamente com intervenções urbanas de teor socioeconômico e educacional podem mitigar os problemas de áreas com vulnerabilidade social, agindo como formador de território e promotor social, para que pudesse ser desenvolvido o projeto de uma estrutura CEU no Conjunto Habitacional Jardim João Domingos Netto em Presidente Prudente. O presente trabalho utiliza a metodologia pautada na pesquisa qualitativa, por meio de pesquisas e revisões bibliográficas. O trabalho aborda questões de programas públicos educacionais que objetivaram a promoção social das comunidades onde inseridos, referencias arquitetônica, justificativa e análise de local para implantação e desenvolvimento de projeto.

Palavras-chave: CEU, Equipamento Urbano, Vulnerabilidade Social, Arquitetura Social, Conjunto Habitacional.

\section{ARCHITECTURE AS A SOCIAL PROMOTER: CENTER FOR ARTS AND SPORTS UNIFIED - HOUSING SET "JARDIM JOÃO DOMINGOS NETTO", PRESIDENTE PRUDENTE - SP}

\begin{abstract}
The Unified Educational Centers (CEUs) are urban equipments aimed at expanding the social insertion of segregated communities in society, by offering education, culture, sport, leisure and vocational courses. The objective of this work was the understanding of how the architecture, together with urban interventions of socioeconomic and educational content can mitigate the problems of areas with social vulnerability, acting as territory trainer and social promoter, so that the design of a CEU structure in the Housing Set Jardim João Domingos Netto in Presidente Prudente. The present work uses the methodology based on qualitative research, through researches and bibliographical revisions. The work addresses issues of public educational programs aimed at the social promotion of communities where inserted, architectural references, justification and analysis of site for implementation and development of the project.

Key words: CEU, Urban Equipment, Social Vulnerability, Social Architecture, Housing Set.
\end{abstract}

\section{INTRODUÇÃO}

Os Centro de Artes e Esportes Unificados, são equipamentos públicos que oferecem a comunidades em situação de vulnerabilidade social "atividades e serviços culturais, práticas esportivas e de lazer, formação e qualificação para o mercado de trabalho, serviços socioassistenciais, políticas de prevenção à violência e inclusão digital" (BRASIL, Ministério do Esporte, 2013, s/p), visando também a promoção da cidadania e modificação social das áreas onde inseridos. Dentro dessa temática, buscou-se retomar projetos educacionais de cunho social, como o projeto da Escola-Parque de Anísio Teixeira até os dias atuais, aprofundando no Centro de Artes e Esportes Unificados - CEU, objeto central desse trabalho.

O Conjunto Habitacional "Jardim João Domingos Netto", recorte geográfico do presente trabalho, é um conjunto habitacional de interesse social, localizado no extremo norte do município de Presidente Prudente - SP, em uma área de 
segregação socioespacial, vulnerabilidade e exclusão social.

O propósito geral do trabalho buscava a elaboração de um espaço arquitetônico que oferecesse experiências culturais, esportivas, profissionalizantes, educacionais e de lazer a toda a comunidade, diminuindo a chance de crianças e adolescentes se envolverem na marginalidade, além de transformar a realidade social nos bolsões de pobreza por meio da inserção social. A presente pesquisa se justifica por si só considerando o atual cenário social, político, econômico e cultural e a área de interesse.

\section{METODOLOGIA}

A fim de compreender acerca da importância dos Centros de Artes e Esportes Unificados o presente trabalho utilizou a metodologia pautada na pesquisa qualitativa, e teve como instrumento de coleta de dados: os levantamentos bibliográficos, antecedentes projetuais, estudos do terreno e estudo preliminar.

Segundo Godoy (1995), a pesquisa qualitativa analisa o objeto em uma perspectiva integrada, ou seja, o pesquisador busca captar o objeto de estudo por meio da perspectiva das pessoas envolvidas, considerando diferentes pontos de vista. Dessa forma não se configura em uma proposta rígida, permitindo que 0 pesquisador explore novos enfoques.

\section{RESULTADOS}

A elaboração de espaços educacionais com o intuito de promover inserção social e equipamentos urbanos em comunidades carentes não é uma prática iniciada tão recentemente. Como precedentes dos Centros de Artes e Esportes Unificados, podemos destacar alguns programas públicos voltados a educação e cultura.

Em 1947 foi construída a Escola-Parque Centro Educacional Carneiro Ribeiro, idealizada por Anísio Teixeira. Considerada como uma instituição pioneira no país combinava educação formal e educação dirigida, onde as turmas iam se alternando de forma que todos os alunos frequentassem ambas as escolas. Enquanto a Escola-Classe cumpria o papel da escola clássica a Escola-Parque oferecia alimentação, banho, atendimento médico e odontológico, atividades artísticas, esportes entre outras atividades. (BASTOS, 2009, apud KOWALTOWSKI, 2011, PEDRÃO, 1999).
0 projeto arquitetônico seguiu 0 programa pedagógico, por meio de edifícios individuais organizados de tal forma que criavam um vazio central e espaços entre os próprios edifícios, onde as crianças podiam desfrutar para jogos e brincadeiras. (PEDRÃO, 1999).

Inspirados pelo modelo inovador de Anísio Teixeira surgiram outros programas como os CIEPs, CIACs, e CEUs. Os Centros Integrados de Educação Pública - CIEPs, foram construídos no Estado do Rio de Janeiro entre os anos de 1983 e 1987, em lugares de grande visibilidade pública. O projeto arquitetônico realizado por Niemeyer, objetivava uma arquitetura em favor de uma transformação educacional e na época era considerado inovador. (GADOTTI, 2000; BARBERI, 2011)

O complexo escolar com capacidade para 1000 alunos, era composto por três edifícios prémoldados, que abrigavam: biblioteca e residência de alunos, o segundo composto de salas de aula, refeitório, ambulatório, enquanto o terceiro abrigava o ginásio de esportes. Apesar de contar com uma boa estrutura pedagógica as trocas de governo, falta de professores e de manutenções fizeram com que os Centros perdessem suas características originais, transformando-se em meras escolas convencionais. (GADOTTI, 2000; BARBERI, 2011)

Assim como nos projetos anteriores, a tentativa de um modelo educacional pioneiro se deu dessa vez em âmbito nacional. Fernando Collor, inaugurou em 1991 os Centros Integrados de Atendimento à Criança e ao Adolescente CIACs, que propunha a construção de novas escolas em tempo integral. Os CIACs projetados por João Figueiras Lima, eram compostos por 5 blocos destinados respectivamente à: oficinas, creche, posto médico, quadra coberta, e por fim escola, biblioteca, cozinha e serviços. Assim como ocorreu na maioria dos programas já expostos devido as mudanças políticas e de governo, os CAICs foram gradualmente abandonados. (SILVA, 2014; CASTRO, 2009; KOWALTOWSKI, 2011)

Por fim temos dois programas com nomenclaturas e objetivos semelhantes, mas que se diferem em relação a escala do programa arquitetônico. Os Centros Educacionais Unificados surgiram em 2001 na cidade de São Paulo com o intuito de levar equipamentos públicos para as áreas de vulnerabilidade social. São complexos educacionais e culturais que rompem os paradigmas de Educação Escolar $\mathrm{x}$ Educação Social, abrindo-se para a comunidade. 
A estrutura não se limita apenas aos blocos educacionais, mas se abre para a população como um espaço de convivência, troca e encontro além de oferecer oportunidades de emprego. (GADOTTI, 2000; BARBERI, 2011)

O programa arquitetônico é dividido em três blocos, sendo o primeiro um pavilhão educacional, que abriga salas de aula, biblioteca, brinquedoteca, refeitório, cozinha, banheiros, espaço de inclusão digital e de convivência. O segundo bloco é destinado a creche, enquanto o terceiro é destinado as atividades de esporte e lazer, abrigando teatro/cinema, sala de música e ginásio. (MACHADO, 2009; BARBERI 2011)

Já os Centros de Artes e Esportes Unificados, foram criados em 2010, por meio do Programa de Aceleração do Crescimento, objetivando um espaço com oferta de atividades e serviços culturais, práticas esportivas e de lazer, cursos profissionalizantes e serviços socioassistenciais, em comunidades carentes. (CEU, 2010)

O programa conta com 3 modelos de projeto, que variam de acordo com o tamanho do terreno onde será implantado, tendo como programa básico: biblioteca, sala de informática, cineteatro, salas de apoio e sanitários, salas multiuso, sanitário, cozinha e ambientes necessários para o funcionamento do Cras. Além disso conta com pista de skate, pista de caminhada, quadra coberta, playground e equipamentos de ginástica. A escolha das áreas para implantação dos equipamentos se dá através de levantamento das áreas de vulnerabilidade social em cidades com no mínimo 50 mil habitantes. (CEU, 2010)

\section{DISCUSSÃO}

Presidente Prudente, é uma cidade média - com cerca de 225.271 habitantes de acordo com o censo de 2010 realizado pelo IBGE. Situada no oeste do estado de São Paulo, foi fundada em 14 de setembro de 1917. No que tange a escolaridade a cidade conta com 24 escolas estaduais, 58 escolas municipais e 42 escolas particulares, apesar de ser uma quantia significativa não se encontram distribuídas com igualdade na malha urbana, concentrando-se em regiões centrais, e deixando as áreas periféricas mais carentes de educação. (PAULA, 2017; PRESIDENTE PRUDENTE. Diretoria de Ensino, 2018).

Segundo Melazo; Cardoso; Magaldi (2017) as áreas periféricas além de indicarem taxas mais altas de analfabetismo possuem outros indicadores de desigualdade social. Dentro do contexto de promoção a cidadania a prefeitura de Presidente Prudente criou a partir de 2011, com o objetivo de mobilização social, desenvolvimento e mudanças em áreas carentes da cidade, as Praças da Juventude e Longevidade da Cohab, Praça da Juventude no bairro Ana Jacinta e no Jardim Humberto Salvador e o primeiro Centro de Artes e Esportes Unificados no Parque Alvorada. (PRESIDENTE PRUDENTE. Coordenadoria da Juventude, 2014)

A justificativa de direcionar um projeto arquitetônico de uma estrutura CEU, no conjunto Habitacional Jardim João Domingos Netto e não em outra área da cidade se deu tomando como base orientações da Coordenadoria da Juventude de Presidente Prudente, que recomendou o bairro Jardim João Domingos Netto como o local carente de equipamentos públicos e que ainda não era atendido pelas Praças da Juventude/Longevidade já existentes na cidade. O Conjunto está localizado no extremo norte do município de Presidente Prudente/SP e faz parte do Programa Minha Casa Minha Vida, Faixa 01. Conta com uma área total de 950.581,63 $\mathrm{m}^{2} \mathrm{e}$ tem seu entorno estruturado por outros loteamentos, como: Residencial Cremonezi, Tapajós e Marangoni, Jardim Morada do Sol e Jardim Santo Expedito I. (SANTOS, 2016)

Após a definição em uma escala macro da área de interesse, o processo de escolha do terreno se deu por meio de um levantamento de todas as áreas institucionais do bairro, delas foram excluídas as áreas já ocupadas ou em processo de ocupação por equipamentos públicos. Os terrenos remanescentes passaram por um filtro considerando dimensões apropriadas, localização do terreno dentro do bairro, proximidade com pontos de ônibus e outros mobiliários urbanos além de contar com fácil acesso para toda a comunidade.

A ideia inicial consiste em projetar pensando no terreno como um todo, de forma que o usuário utilize o lote em geral ao invés de focar apenas na edificação. Outro aspecto que norteia o projeto é a intenção de que ele abrace a comunidade, nessa linha de raciocínio chega-se à conclusão de que nenhum outro elemento é tão público e democrático quanto as praças. Dessa forma o conceito proposto está pautado no desenvolvimento de um edifício-praça, como extensão da casa e da cidade, de forma que o edifício e o lote complementam um ao outro. 
O programa de necessidades proposto teve como base o projeto básico do CEUs, porém novos ambientes foram acrescentados enriquecendo a ideia multi-programática do edifício. $O$ resultado final do programa consiste em 4 setores, sendo: apoio e serviço (DML, depósito de lixo, área dos colaboradores e sanitários), setor de acolhimento (recepção, sala de atendimento, almoxarifado, sala administração, sala coordenação, sala multiuso, copa e sanitário), setor educacional e cultural que abrange a biblioteca, sala de informática, cineteatro, oficinas, ateliês, depósito, cozinha experimental, área de serviço e sanitários. E por fim o setor esportivo contempla o playground, pista de skate, quadra poliesportiva, equipamentos de ginástica, pista de caminhada,

Figura 1. Forma bloco edificado

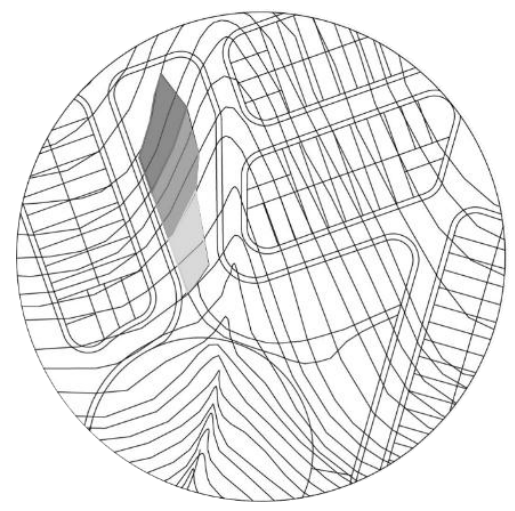

Fonte: da autora (2018)

A utilização da cobertura como terraço jardim, permite a criação de mirantes que se abrem tanto para a APP quanto para o bairro em geral, tornando um espaço de contemplação

Figura 4. Esquema de caminhos

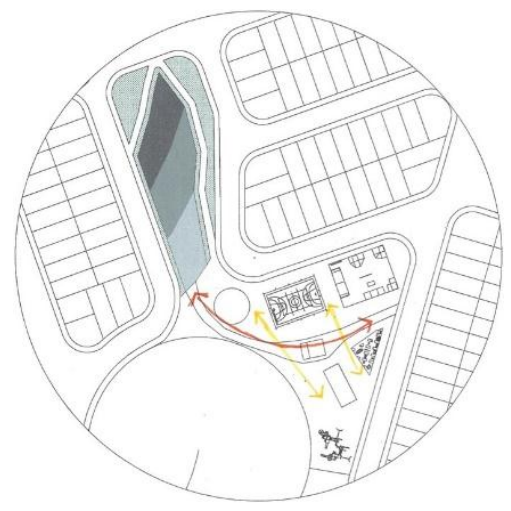

Fonte: da autora (2018) piscina, vestiário/sanitário e depósito de material esportivo.

O volume do bloco edificado originou-se do desenho das próprias curvas de nível existentes no terreno. Após definição do perímetro e verificação de que a área era suficiente para acomodar o programa, foi definido a utilização de pavimentos em níveis intermediários. Além de possibilitar um melhor conforto térmico, o fato de criar um edifício em níveis intermediários aproveitando a topografia original permite a utilização da cobertura como terraço jardim. E por fim o bloco respeita o gabarito de altura do seu entorno - onde todos os edifícios possuem apenas um pavimento -, dialogando com as construções existentes.

Figura 2. Corte esquemático

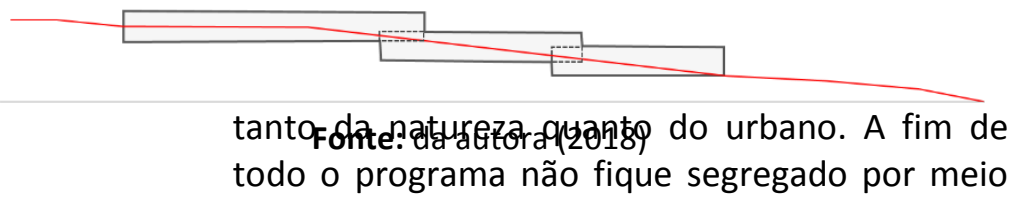

Figura 3. Diagrama mirantes

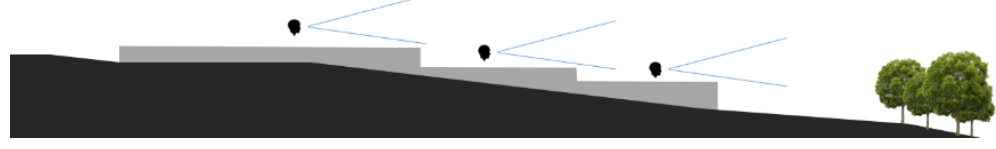

Fonte: da autora (2018)

da implantação e da própria conformação do terreno, busca-se criar caminhos que cruzem o lote por todos os sentidos.

Figura 5. Esquema de implantação

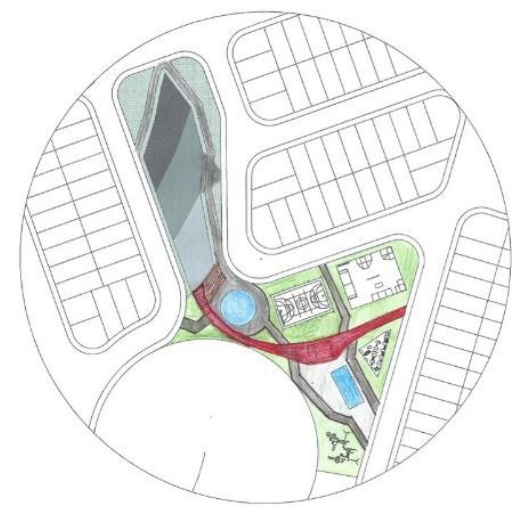

Fonte: da autora (2018) 
O sentido demonstrado pela seta vermelha no esquema anterior, apresenta um elevado desnível natural do terreno. Dessa forma, uma passarela sem inclinação alguma liga a laje do mirante mais baixo, com o solo do próprio lote. Além de funcionar como um elemento integrador e caminho acessível, a passarela cria um caminho coberto para quem se encontra no nível do solo, além de funcionar como cobertura do depósito de materiais esportivos e vestiários, contribuindo para que a linguagem arquitetônica do edifício se estenda para as demais construções.

\section{CONCLUSÃO}

O presente trabalho possibilitou um maior conhecimento sobre os assuntos e temáticas abordados, podendo-se destacar programas públicos que objetivavam a promoção social das comunidades onde eram inseridos, alguns sendo bem sucedidos já outros nem tanto. Permitiu também o conhecimento de diferentes projetos com soluções arquitetônicas interessantes dentro do conceito do projeto.

Partindo da ideia de respeito, valorização, democracia e igualdade entre os seres, o trabalho foi desenvolvido cumprindo seu principal objetivo: direcionar projetualmente um edifíciopraça que atuasse com um programa multiprogramático, ofertando atividades de esporte, cultura, lazer e educação para todas as faixas etárias da comunidade, melhorando tanto a vida em comunidade quanto o ambiente construído.

\section{REFERÊNCIAS}

BARBERI, F. F. Os Centros Educacionais Unificados (CEUs) da Prefeitura Municipal de São Paulo e o rendimento escolar dos alunos. 2011. 110 f. Dissertação (Mestrado em Educação: História, Política, Sociedade) - Pontifícia Universidade Católica de São Paulo, São Paulo SP, 2011.

BRASIL. CEUs. Conheça os Ceus: O programa. Brasília, 2011. Disponível em: < http://ceus.cultura.gov.br/index.php/conheca-osceus/o-programa>. Acesso em: 27 fev. 2018.

BRASIL. Ministério do Esporte. Praça da Juventude: a inclusão social como exercício diário de cidadania. Brasília, 2013. Disponível em: $<$ http://portal.esporte.gov.br/institucional/secret ariaExecutiva/pracaJuventude/sobre.jsp >. Acesso em: 10 jul. 2018.
CASTRO, C. D. M. S. O espaço da escola na cidade CIEP e arquitetura pública escolar. 2009. $136 \mathrm{f}$. Dissertação (Mestrado em Arquitetura e Urbanismo) - Faculdade de Arquitetura e Urbanismo - UnB, Brasília - DF, 2009.

GADOTTI, M. Educação com qualidade social: projeto, implantação e desafios dos Centros Educacionais Unificados (CEUs). São Paulo: Instituto Paulo Freire, 2000. $26 \mathrm{f}$.

GODOY, A. S. Pesquisa Qualitativas: Tipos Fundamentais. Revista de administração de empresas, São Paulo, v. 35 , n. 3, p. 20-29 maio/jun. $1995 . \quad$ Disponível em: <http://www.scielo.br/pdf/rae/v35n3/a04v35n3 >. Acesso em: 10 jul. 2018.

KOWALTOWSKI, D. C. C. K. Arquitetura escolar: o projeto do ambiente de ensino. São Paulo, SP: Oficina de Textos, 2011.

MACHADO, D. S. C. Público e comunitário: projeto arquitetônico como promotor do espaço de convivência. 2009. 144 f. Dissertação (Mestrado) - Universidade São Judas Tadeu, São Paulo-SP, 2009.

PAULA, Histórico do Município. In: UNIVERSIDADE ESTADUAL PAULISTA JÚLIO DE MESQUITA FILHO. Atlas Ambiental Escolar de Presidente Prudente. Presidente Prudente, $2017 . \quad$ Disponível em: $<$ http://portaldoprofessor.fct.unesp.br:9000/topi co/formacao-socioespacial/>. Acesso em: $23 \mathrm{abr}$. 2018

PEDRÃO, A. W. A Escola-Parque, uma experiência projetual arquitetônica e pedagógica. Revista Rua, Salvador, 1999 n. 7, p. 24-29

PRESIDENTE PRUDENTE. Coordenadoria da Juventude. Disponível em: < http://www.presidenteprudente.sp.gov.br/site/u nidade.xhtml?cod=26>. Acesso em: 27 abr. 2018

PRESIDENTE PRUDENTE. Diretoria de Ensino. Escolas. 2018. Disponível em: < https://depresidenteprudente.educacao.sp.gov.b r/escolas/>. Acesso em: 23 abr. 2018.

SANTOS, F. C. A. S. Espaço, tempo e contradições: do Banco Nacional de Habitação 
ao Programa Minha Casa, Minha Vida em Presidente Prudente/SP. 2016. 1 CD-ROM. Trabalho de conclusão de curso (Bacharelado Geografia) - Universidade Estadual Paulista, Faculdade de Ciências e Tecnologia, 2016.

SILVA, N. S. Sobre a invenção dos próprios fins: Gestão híbrida nos Centros Educacionais Unificados (CEUs). 2014, 180 f. Dissertação (Mestrado em Ciência da Informação) - Escola de Comunicações e Artes, Universidade de São Paulo, São Paulo, SP, 2014.

Recebido para publicação em 09/08/2018

Revisado em 13/08/2018

Aceito em 15/08/2018 